\title{
Memory for the pitch of a tone'
}

Observers attempted to detect the presence of a pitch difference between two successive tones. The percentage of correct judgments was equivalent for tones separated by 95 , 4.5 , and $8.9 \mathrm{sec}$. There was a general increase in reports of a pitch difference with increased intertone interval, which is interpreted as arising from hypothesized shifts in the neural locus of the first stimulus during the intertone interval.

The ability of human observers to accurately recall the pitch of a tone has received sporadic attention since the earliest days of experimental psychology. It is typically indexed by relating variations in the accuracy with which the pitch of two successive tones is discriminated to the time interval separating them. Koester (1945) found pitch memory to decline with increasing intertone interval, while other investigators (Anderson, 1914; : Angell \& Harwood, 1899; Whipple, 1901) have reported no change, and Irwin (1937) has presented data suggestive of improved accuracy with increased separation time. Some of these contradictions can reasonably be attributed to the unrefined psychoacoustic equipments available to the early investigators. Recently Bindra, Williams, \& Wise (1965) sought to vary the difficulty of a pitch discrimination problem by employing different intertone intervals. The data indicated a higher error rate with the greater interval (10 vs. 1 sec.), and a higher error rate when the tones were the same than when they were different. The authors interpret their findings within the framework of statistical decision theory (Swets, Tanner, \& Birdsall, 1961). However, the ease of the discrimination employed (60 cps intertone difference) resulted in such a low error frequency (about nine per cent) that interpretations of the data must be quite tentative. For example, it is a distinct possibility that with such a large frequency difference, errors more often arose from momentary lapses in attention than from variations in either the underlying sensory mechanisms or the Ss' decision rules. In the research here reported pitch memory was investigated utilizing three intertone intervals in conjunction with pitch differences small enough to generate a sizable error frequency.

\section{Subjects}

\section{METHOD}

Six navy recruits with normal hearing were used as Ss.

\section{Apparafus}

Pure tones were generated by two Hewlett-Packard $201 \mathrm{CR}$ audio oscillators and were filtered by an Allison 2BR filter set to 720 cps high pass and 920 cps low pass. One oscillator was set to produce the first tone of 800 cps, and the other to produce a second stimulus of a different frequency. The oscillators were calibrated after each 51 stimulus presentations on a 5233L Hewlett-Packard electronic counter. The intertone intervals were controlled by a 1431 Lafayette eight bank program timer, and the tonal durations by two 1001 Lafayette interval timers. Another timing circuit was initiated at the termination of the second tone. It served to activate a signal-light 8 sec. later, which was a cue to $E$ to announce the next item. The tones were fed through a Model 240 McIntosh amplifier to eight Sharpe Instrument HA-10 headsets. The duration and intensity of the tones were calibrated by displaying them on a 564 Tektronix storage oscilloscope. Signal intensity at the headsets was computed to be approximately $84 \mathrm{db}$.

\section{Procedure}

Training. Several days before the experiment began, all Ss were given approximately $1-1 / 2 \mathrm{hr}$. of instruction on the nature of the experiment, including practice with feedback on each of the discriminations which they would subsequently be required to make. Immediately preceding the first day of the study, each $\mathrm{S}$ was given an additional $45 \mathrm{~min}$. of individual training.

\section{Experimental Conditions}

An item consisted of two successively-presented $.95-\mathrm{sec}$. duration tones. The first tone was always set at $800 \mathrm{cps}$, and the second differed from the first by $0, \pm 3, \pm 4, \pm 5$ cps. Each $S$ made 1,836 judgments. On half of these he judged whether the second tone was higher or the same as the first and on the other half whether it was lower or the same. Equal numbers of the higher stimuli were 3,4 , and $5 \mathrm{cps}$ above the standard, and equal numbers of the lower stimuli were 3 , 4 , and 5 cps below the standard. A trial block consisted of 306 judgments and on any trial block the amount and direction of the frequency difference was constant. Rest periods were given following each 51 judgments, and one trial block was mun each day. Each amount and direction of frequency difference occurred on a different day for the six Ss. Intertone intervals of .95, 4.5 , and $8.9 \mathrm{sec}$. occurred an equal number of times, and this variable was randomly distributed over the judgments in a trial block. The particular intertone interval for an item was announced prior to its presentation. The Ss were informed of the fact that on any trial the probabilities of the second tone being the same as or different from the first were equal. Ss gained and lost points equally for correct judgments and errors. Net points gained were convertible into time-off from the military establishment. Before each trial block, Ss were informed of how many net points they had accumulated. 


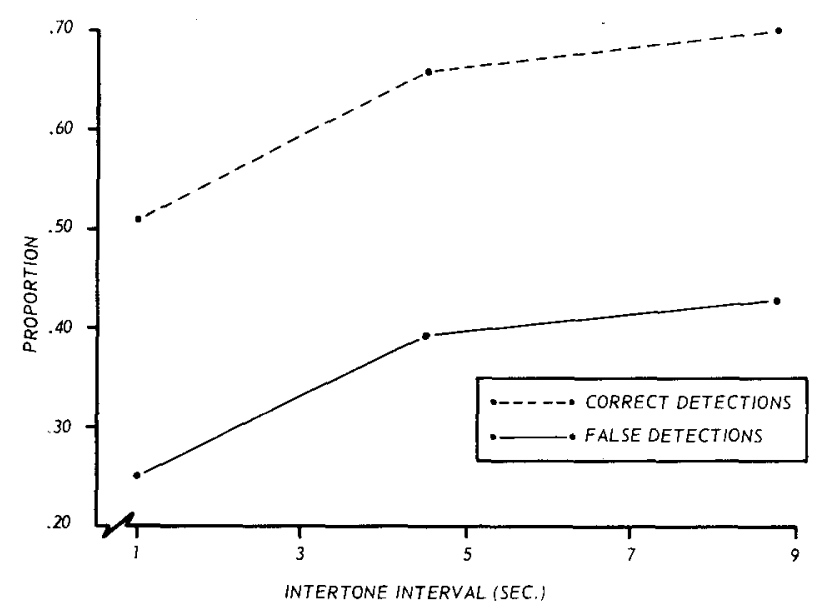

Fig. 1. Proportion of correct detections (tones different/judged different) and false detections (tones same/judged different) as a function of the intertone interval.

\section{RESULTS AND DISCUSSION}

\section{Pitch Discriminability}

The proportion of correct judgments for each $S$ in each trial block were computed and transformed to arcsines to stabilize the variances. These scores were then subjected to an analysis of variance involving amount of frequency difference, direction of frequency difference, and intertone interval. The only reliable source of variance was that associated with the frequency difference separating the stimuli $(F=6.27, \mathrm{df}=$ $2 / 10, \mathrm{p}<.02)$, which showed the expected increase in discriminability with increasing frequency separation. The variable of greater interest, intertone interval, produced virtually no variation. For $.95,4.5$, and $8.9 \mathrm{sec}$., the percentages correct were $.63, .63$, and .64 , respectively.

\section{Types of Errors}

In this sort of detection experiment, an error may consist of either an incorrect report of a pitch difference (false detection) or a failure to report a difference (detection failure). The proportion of the trials on which the stimuli were of the same pitch but incorrectly reported as different were converted to arcsines for each $\mathrm{S}$ and submitted to an analysis of variance. As expected, false detections showed a reliable decline with increasing frequency difference between the stimuli $(F=3.96$, $\mathrm{df}=2 / 10, p=.05)$. However, in addition this measure was reliably related to the intertone interval $(F=5.60$, $\mathrm{df}=2 / 10, \mathrm{p}<.02$ ). For $.95,4.5$, and 8.9 sec. the proportions of false detections were $.25, .39$, and .43 , respectively. Since the proportion of correct response remained constant over the various intertone intervals, such an outcome requires a corresponding increase in the proportion of items containing a pitch difference which were correctly reported (correct detections). The relationship of these two measures to intertone interval is shown in Fig. 1. It is clear that the Ss increased their rate of reporting a pitch difference as the interval separating the stimuli increased. The proportion of reports of a pitch difference, independent of its correctness, were $.39, .51$, and .56 for the $.95,4.5$, and $8.9 \mathrm{sec}$. intertone intervals, respectively. From the standpoint of signal detectability theory (Swets, Tanner, \& Birdsall, 1961) the Ss were apparently adopting a conservative criterion for reporting a difference at the $.95 \mathrm{sec}$. separation, and then progressively relaxing it as the interval lengthened. However, signal detectability theory makes the value of the criterion depend only on the a priori probability of the event to be detected and the values and costs associated with the decisions. Since neither factor was varied as the intertone interval increased, there is no good reason for such a change.

An alternate interpretation ${ }^{2}$ can be obtained by assuming a constant decision rule over the intertone intervals, and looking upon the data as reflecting variations in sensory mechanisms. If the low reporting of a difference at the $.95 \mathrm{sec}$. interval is looked upon as simply reflecting the very difficult discriminations required, the principal problem becomes one of accounting for the increase in such reports at the greater separations. Assume that something akin to the satiation some have hypothesized as underlying figural aftereffects is also operative in the auditory system. It will be recalled that the experimental procedure involved the presentation of only two stimulus frequencies during any 306-item trial block. The first stimulus was always set at $800 \mathrm{cps}$, while the second was half the time the same and half the time a fixed frequency distance and direction from the first. If during the course of a trial block, the repeated exposure to only two frequencies resulted in areas of auditory satiation then it could be hypothesized that stimuli subsequently arriving at these same pitch loci would be displaced from them. With the additional assumption that the extent of displacement of the first stimulus increases for some period of time following its arrival at the satiated area, an account of the data is obtained. Thus, on trial blocks in which the second stimulus was either the same or higher than the first, the first stimulus would be increasingly displaced to a lower pitch locus as the intertone interval increased. The discriminatory responses predicted from these assumptions are as the data indicate, i.e., an increased tendency to both correctly and incorrectly report a pitch difference as the intertone interval increased, without a corresponding change in discriminability. The same interpretation would, of course, apply to trial blocks in which the second stimulus was either the same or lower than the first.

Although this hypothesis was constructed from the data, it appears to have some clearly testable consequences. Anything which would serve to control the degree of hypothesized satiation, (e.g., duration of pre-exposure to a fixed frequency, length of trial blocks without rest), should increase the tendency 
to report pitch differences, particularly if the Ss are given no information on the a priori probability of a difference. As for the increasing displacement of the first stimulus with time following its termination, the data in Fig. 1 indicate that if such does take place it is leveling out at about 9 sec. From the data which suggest that stimulus generalization functions flatten with time (Thomas \& Lopez, 1962; Aiken \& Gibson, 1965) one might predict that with further increases in the intertone interval an opposite response bias would develop, i.e., a tendency to falsely report stimuli which are different as the same. Research with a wider range of intertone intervals is indicated.

\section{References}

Aiken, E. G., \& Gibson, K. L. Continuous and fixed reinforcement effects in extinction one day and three weeks after acquisition. Psychon. Sci., 1965, 3, 527-528.

Anderson, D. A. The duration of tones, the time interval, the direction of sound, darkness and quiet, and the order of stimuli in pitch discrimination. Psychol. Monogr., 1914, 16, No. 16.

Angell, F., \& Harwood, H. Experiments on discrimination of clangs for different intervals of time. Amer. J. Psychol, 1899, 11, 65-69.
Bindra, D., Williams, J. A., \& Wise, J. S. Judgments of sameness and difference: Experiments on decision time. Science, 1965 150, 1625-1627.

Irwin, C. C. A study of differential pitch sensitivity relative to to auditory theory. J. exp. Psychol., 1937, 21, 642-652.

Koester, $\mathbf{T}$. The time error and sensitivity in pitch and loudness discrimination as a function of time interval and stimulus level. Arch. Psychol., N. Y., May 1945, No. 297.

Swets, J. A., Tanner, W. P. Jr., \& Birdsall, T. G. Decision processes in perception. Psychol. Rev., 1961, 68, 301-340.

Thomas, D. R., \& Lopez, L. J. The effects of delayed testing on generalization slope. J. comp. physiol. Psychol., 1962, 55, 541544.

Whipple, G. M. An analytical study of the memory image and the process of judgment in the discrimination of clangs and tones. Amer. J. Psychol., 1901, 12, 409-457.

\section{Notes}

1. The opinions and assertions contained herein are those of the writers and are not to be construed as official or as reflecting the views of the Navy Department or naval service.

2. The authors are grateful to Dr. C. T. White of the U. S. Navy Electronics Laboratory for suggesting this line of reasoning.

(Received in Editorial Office May 16, 1966.) 